\title{
COMO USAR DE FORMA CRIATIVA O GOOGLE EARTH, MAPS, STREET VIEW E DESE- NHOS MANUAIS DE MAPAS NAS AULAS DE CARTOGRAFIA
}

\author{
Alcimar Paulo Freisleben*, Nestor André Kaercher ${ }^{* *}$ \\ * Doutorando no POSGEA-UFRGS, Mestre e Licenciado em Geografia pela UNIOESTE -FB. \\ ***ofossor do Programa de Pós-graduação em Geografia e da Faculdade de Educação da UFRGS; E-mail: nestorandrek@gmail.com
}

Recebido em 10/2014. Aceito para publicação em 04/2015.

Versão online publicada em 13/01/2016 (http://seer.ufrgs.br/paraonde)

\begin{abstract}
Resumo: Neste trabalho é apresentado o resultado do estágio docente do mestrado com alunos da disciplina de Cartografia Geral e Temática do curso de Licenciatura em Geografia da Unioeste (Francisco Beltrão, Paraná, Brasil), realizado em 2012. 0 objetivo das aulas foi proporcionar aos alunos do primeiro ano da licenciatura os conhecimentos básicos, teóricos e práticos para compreenderem as representações cartográficas mediante o uso da cartografia digital. A metodologia utilizada foi a apresentação (para o posterior uso) dos programas do Google como Earth, Maps e Street View, intercalados com desenhos manuais, aplicados à elaboração de mapas temáticos nas aulas de Cartografia. 0 resultado alcançado foi a capacitação básica desses alunos no uso de novos instrumentos didático sproporcionados pelas tecnologias da informação e a computação e úteis para as aulas de Geografia.
\end{abstract}

Palavras-chave: Cartografia digital, mapas, imagens, tecnologias..

\section{Introdução}

Os desafios na área da educação superior são inúmeros, entre eles destacamos a constante necessidade de atualização e de domínio de novos recursos tecnológicos. 0 domínio das tecnologias da informação é muito solicitado ao professor da Cartografia, pois cada vez mais o uso de mapas digitais e imagens de satélite fazem parte do cotidiano das aulas.

Segundo Martinelli (1999), a ciência dos mapas também não pode ser vista fora do contexto da era da informação da qual desponta como conceito central, o de visualização cartográfica, tido como uma forma de amalgamar os entendimentos da Cartografia associados à análise, à comunicação e às tecnologias computacionais.

Porém muitos professores, não têm conseguido acompanhar o avanço da ciência geográfica e assim ficam presos aos manuais, que mantêm uma interpretação por descrição e classificação dos elementos da realidade, negando a diversidade de contextos nos quais os alunos estão inseridos.

Com base nesta visão, nós professores de Geografia, buscamos referências bibliográficas e recursos educativos além do livro didático, para trazer elementos significativos ao cotidiano dos alunos para a sala de aula, fazendo assim com que os mesmos interajam e construam o saber geográfico.

Pretendemos destacar, neste trabalho, a importância de um ensino atualizado com as tecnologias, que busque ampliar a curiosidade e a capacidade de pesquisa do aluno nas aulas de Cartografia/Geografia, através da integração de recursos tecnológicos como a informática; utilizando programas gratuitos, do Google..

\section{As tecnologias digitais na Cartografia}

A Lei de Diretrizes e Bases da Educação (BRASIL, 1996) cita que o dever do governo com a educação escolar pública, será efetivado mediante a garantia de padrões mínimos de qualidade de ensino, definido como a variedade e quantidade mínimas por aluno, de materiais indispensáveis ao desenvolvimento do processo de ensino-aprendizagem como um todo. Sendo inquestionável o uso da informática no processo de ensinoaprendizagem nas escolas.

Segundo Pierre Lévy (1993) o conhecimento poderia ser apresentado de três formas diferentes: a oral, a escrita e a digital. Embora as três formas coexistam, torna-se essencial reconhecer que a era digital vem se apresentando com uma significativa velocidade de comunicação. Neste processo de enfrentamento oriundo do avanço da tecnologia, a escola não passa impune.

0 instrumental tecnológico disponível na internet, como o Google Earth, Google Maps, Google Street View entre outros, também podem ser importantes recursos da Cartografia.

Neste âmbito, a Geografia pode e deve se utilizar de práticas pedagógicas vinculadas às imagens e tecnologias de comunicação e informação no intuito de tornar suas aulas mais dinâmicas e interessantes. 


\section{Metodologia}

A turma onde foi executado o estágio de docência era composta por cerca de 35 alunos, uma grande parte de jovens trabalhadores provenientes de escola pública. No primeiro dia da regência, após a apresentação e breve exposição do que consistia o trabalho e o mestrado de Geografia, mostramos aos alunos a metodologia que seria utilizada durante as aulas, que seriam: aulas expositivas e práticas em laboratório, dialogadas e interativas e elaboração de trabalho individual para ser entregue no último dia das atividades, e que se tratava da confecção de três mapas com o trajeto casa/universidade do aluno (ou casa/ponto do ônibus/van para os alunos de outras cidades), um mapa deste trajeto deveria ser confeccionado a mão (com título, legendas, pontos de referência, nome das ruas, localização do Norte etc.); um outro mapa do mesmo trajeto deveria ser feito com o Google Maps (e complementado com o trajeto destacado, legendas, Norte e pontos de referências), e mais um mapa do trajeto no Google Earth. Também solicitamos uma imagem de uma cidade no Google Street View (programa que mostra imagens - ao nível do solo - feitas com várias câmeras simultaneamente).

Posteriormente estas imagens deveriam ser impressas e entregues para avaliação e depois anexadas ao portfólio, para ser utilizado durante toda docência.

Após esta introdução vimos um vídeo do site da TV Escola, sobre tecnologias na Cartografia, o vídeo mostrava a história da Cartografia Antiga até a Cartografia Digital atual, com várias explicações de professores e especialistas da área.

Para Castellar (2000), a Cartografia é considerada uma linguagem, um sistema-código de comunicação, imprescindível em todas as esferas da aprendizagem em Geografia, articulando fatos, conceitos e sistemas conceituais que permitem ler e escrever as características do território. Nesse contexto, ela é uma opção metodológica, o que implica utilizá-la em todos os conteúdos da Geografia, para identificar e conhecer não apenas a localização dos países, mas entender as relações entre eles, compreender os conflitos e a ocupação do espaço.

Ao final do vídeo, tecemos comentários e começamos a discutir as possibilidades didáticas do Google Earth, primeiramente com uma demonstração do programa através de uma projeção no quadro com o data show e depois através da prática individual orientada, diretamente no computador (como faltaram 5 computadores, alguns alunos trabalharam em duplas). Observamos que alguns alunos dominavam a informática e o programa, outros nem a informática nem o programa, com esta discrepância o ritmo da aula foi um pouco abaixo do planejado.

Para Morin (1997), a disseminação da informação através da informática permite diversas aplicações educacionais, seja na divulgação, na pesquisa, no apoio ao ensino, entre outras. 0 autor salienta que hoje, a distância principal não é a geográfica, mas a econômica, a cultural, a ideológica e a tecnológica.

No final da primeira aula lembramos aos alunos a importância de usarem o programa em casa ou na própria universidade para melhorar o conhecimento, principalmente para aqueles que não dominavam o programa, ressaltamos também a importância da cooperação dos colegas mais habilidosos com os demais.

$\mathrm{Na}$ aula seguinte apresentamos em PowerPoint, o material intitulado: 0 Uso do Programa Google Earth na Produção do Conhecimento Geográfico: uma proposta para utilização das tecnologias espaciais, da Universidade Federal do Ceará, que demonstrava as possibilidades didáticas do programa em aula de Geografia Regional.

Após a apresentação, continuamos com a prática do programa Google Earth alternado com o Google Maps (imagens no 01 e no 02). Os alunos aprenderam noções de latitude/longitude, orientação, reconhecer biomas e relevo, identificar problemas ambientais e especulação imobiliária em áreas protegidas e também aprenderam salvar as imagens e continuaram em sala a confecção do trabalho.

As aulas já possibilitavam aos alunos a confecção do trabalho, o que foi feito por todos, já que a conexão da internet em casa não era suficientemente rápida para a navegação nos programas que trabalhamos no laboratório de informática.

Na aula no laboratório de informática, apresentamos uma parte do vídeo do site da TV Escola sobre a história dos mapas, de 1.000 a.C. até o Google Earth, as funções dos mapas e a influência do contexto político e cientifico para a evolução da Cartografia e vimos um material com dicas de como usar o Google Street View.

Outro site que apresentamos aos alunos, foi de um trabalho artístico com imagens retiradas de fotografias feitas pelos carros do Google Street View.

O Google Street View pelo seu aspecto visual e pela interatividade, foi o que mais chamou a atenção dos alunos, um deles descobriu que as imagens do programa não se restringia as capitais brasileiras, mas que já estavam disponíveis as de cidades de nossa região.

A utilização da internet na educação é uma questão bastante polêmica que tem motivado o trabalho de grande número de pesquisadores no mundo todo. Com a chegada da rede mundial de computadores, passamos a conviver com uma ferramenta de comunicação que ultrapassou as barreiras de tempo e espaço, utilizando apenas um computador conectado à internet (VIDAL, 2002).

É um recurso que professores e alunos estão aprendendo a usar. As aplicações da internet na educação são praticamente inesgotáveis e dependem basicamente da criatividade do educador.

Embora não seja a solução absoluta para os problemas da educação a internet é uma grande facilitadora da pesquisa e comunicação entre os participantes do processo ensino-aprendizagem. Não basta incorporar os modernos recursos, é preciso integrá-los efetivamente aos fundamentos de uma nova educação (VI 


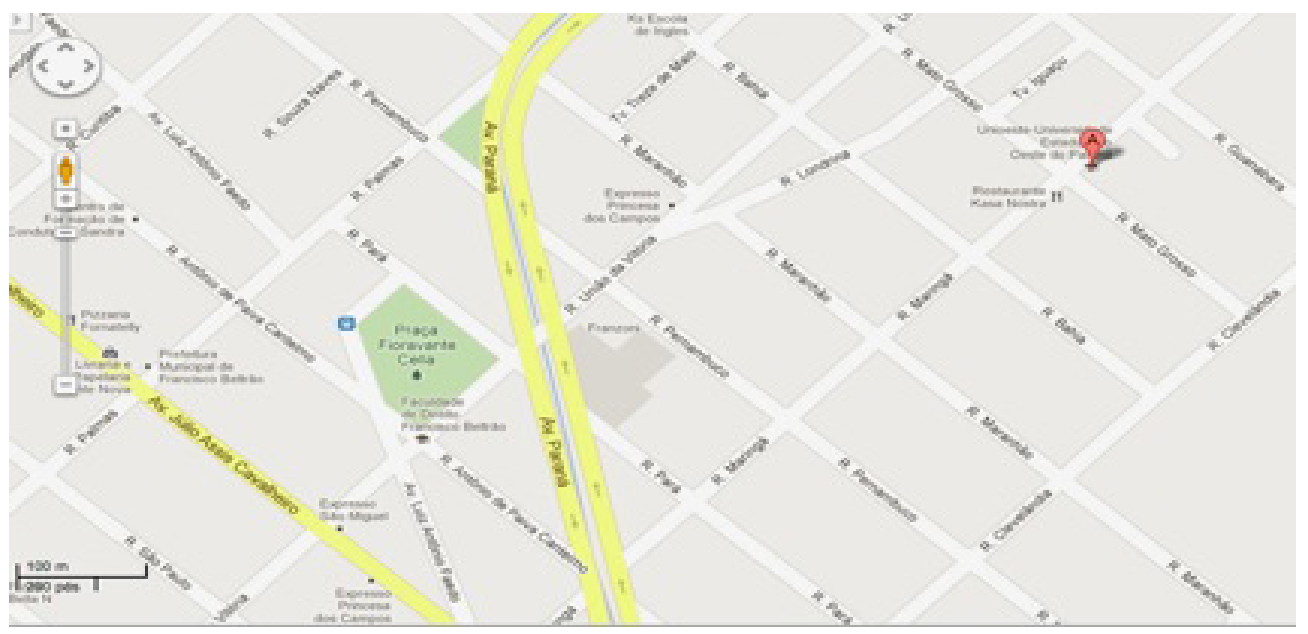

Fonte: Imagem do Google Maps

Imagem no 02 - Bairro Vila Nova - Fco. Beltrão/PR

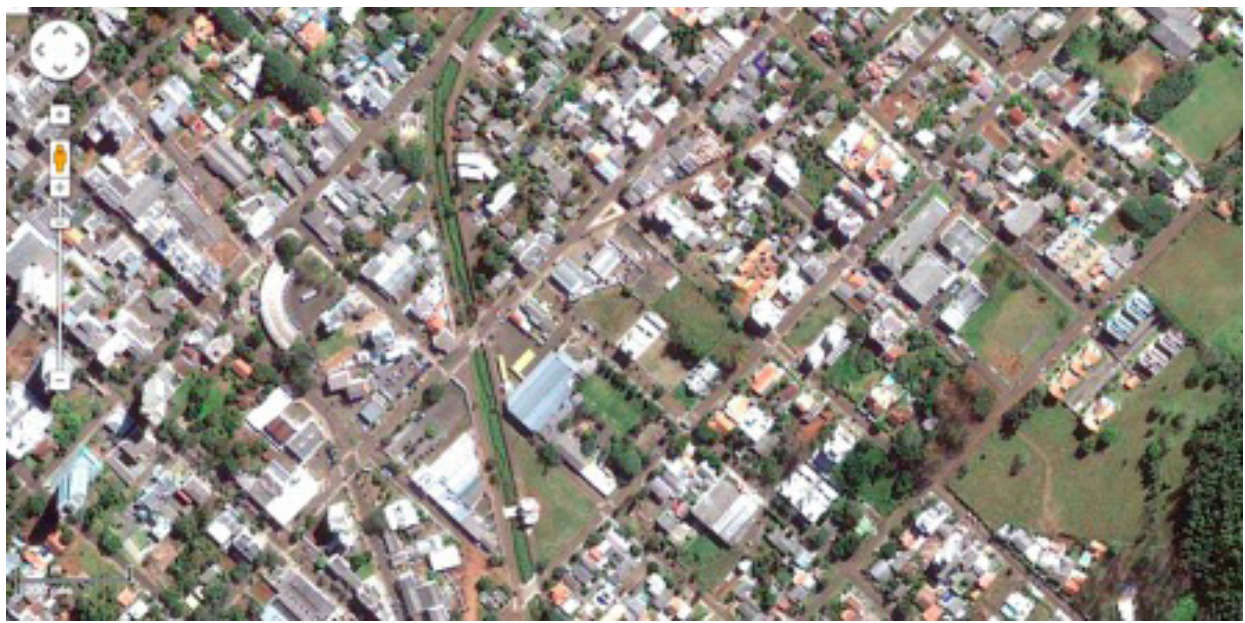

Fonte: Imagem do Google Earth

Imagem no 03 -. Ilha Sanday - Escócia

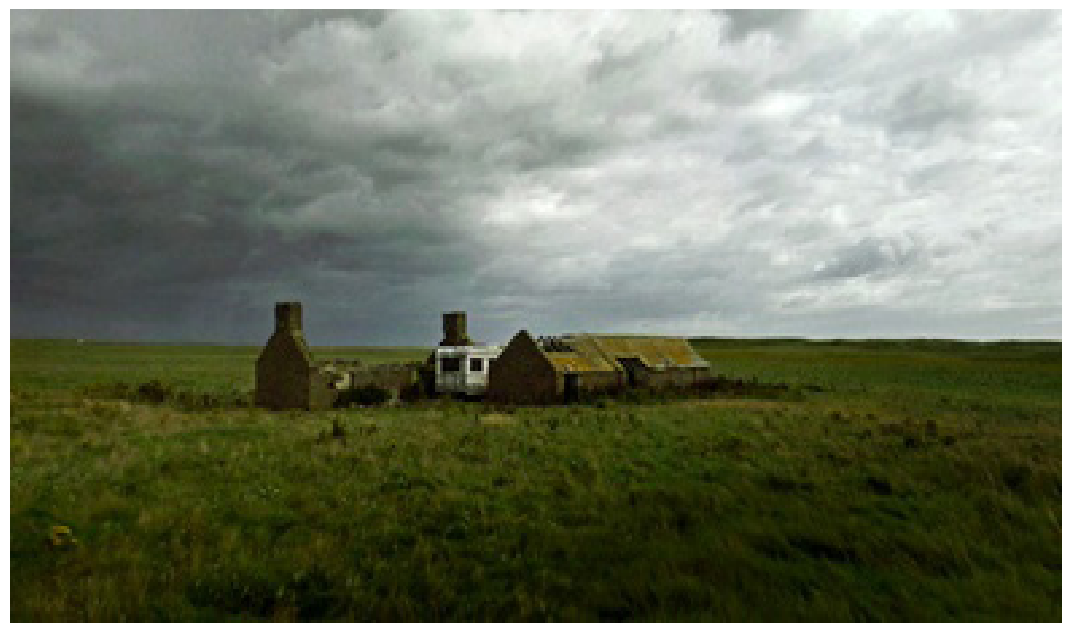

Fonte: "Fotografia" de imagem do Google Street View http://www.aaronhobson.com/streetview.html

\section{DAL, 2002).}

Os alunos, no geral, são entusiastas de tudo que se refere a internet e tecnologias, e os nossos não fugiam a regra, estavam fascinados com a possibilidade de fazer este tour virtual por cidades onde nunca estiveram, as- sim a leitura daquelas imagens foi prazerosa para eles, conforme a imagem na sequência.

No que se refere a leitura de mapas Petchenick (1995), afirma que "toda percepção é também pensamento, toda razão é também invenção". Ressalta que 
apesar das ciências estarem avançadas, ainda não existe uma teoria completa para a leitura de mapas. Para a autora, a leitura do mapa não consiste em simplesmente uma soma de comparações perceptivas simples, de tamanho ou valor simbólico. Apesar de nos últimos anos várias teorias novas terem surgido e influenciado a Cartografia, elas ainda não foram suficientes para tornar mais eficaz o processo de leitura de mapas.

Ainda seguindo esta linha de pensamento, a autora afirma que está surgindo um novo enfoque, formado através do processo mental do homem que cada um constrói ao longo da vida. Sob este ponto de vista, os meios de comunicação, tal como a linguagem e os mapas, não carregam significados, ou melhor, eles desencadeiam o processo. Para Petchenick (1995), os mapas mentais não são simplesmente arranjos de mapas cartográficos, eles vão muito além do que se pode observar através do olhar, "é uma representação integrada", englobando várias representações que ajudam a interpretar a realidade ao redor.

De acordo com Wood (1992), torna-se importante salientar que, um mapa não é a realidade e não nos deixa ver coisa nenhuma, mas ele deixa-nos saber, o que outras pessoas viram, acharam ou descobriram. Salienta que, mapas são realmente caricaturas científicas do fenômeno que eles representam. Os detalhes e a complexidade da realidade são selecionados, simplificados e, em seguida, enfatizados de uma maneira que eles apenas retratam o que o fazedor do mapa acredita ser essencial a respeito do espaço referido no mapa (WOOD, 1992, p.333).

Para Costella e Schaffer (2012) nas aulas de Geografia é preciso investigar como os alunos imaginam que seja o espaço que convive cotidianamente.

A evocação do imaginário é uma forma de representar, de pensar sobre o espaço, que se constitui de elementos e relações a partir dos quais os quadros mentais começam a se formar, organizando um conjunto inter-relacionado de elementos que dará origem a paisagens, a espaços mentalmente projetados (COSTELLA e SCHAFFER, 2012, p. 51).

Apesar da facilidade de atualmente conseguirmos pela internet fotografias e mapas de praticamente qualquer parte do planeta, a confecção de mapas (de lugares cotidianos) desenhados pelos próprios alunos, pode ser um instrumento didático importante no aprendizado de Geografia/Cartografia, já que trabalham com inteligências mais relacionadas as habilidades artísticas, a memória e a imaginação.

Imagem no 04 - Alunos “viajando" através do Google Street View

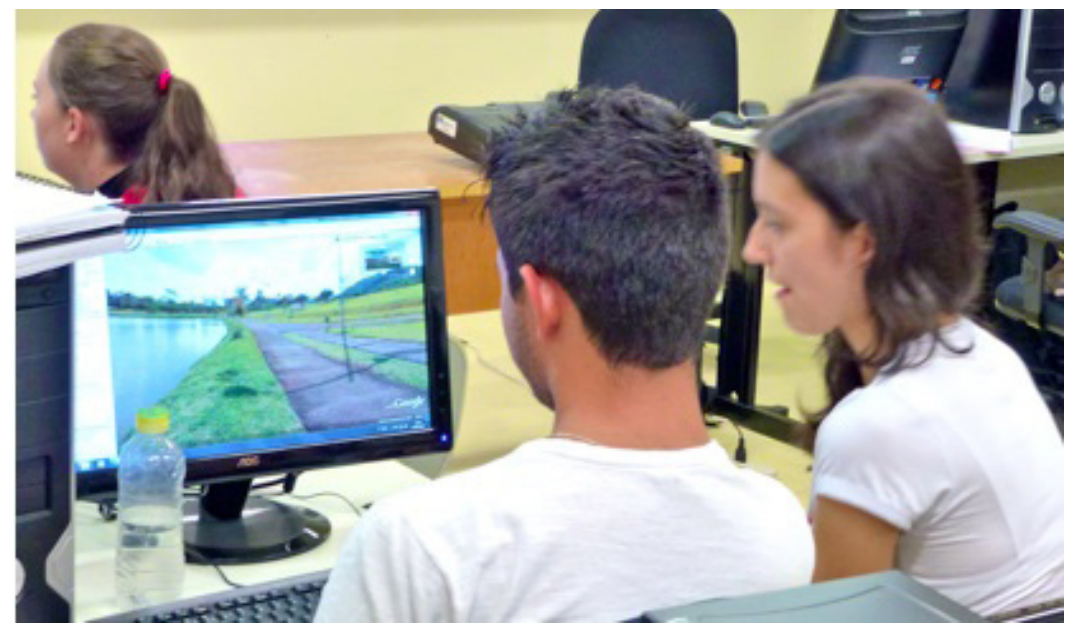

Imagem no 04 - Alunos “viajando" através do Google Street View

\section{Confeccionando os próprios mapas}

0 uso de mapas cartográficos sempre esteve associado à Geografia, mas não se pode aceitá-los como meras ilustrações. Muitos professores no Ensino Fundamental, Médio e Universitário utilizam os mapas enquanto recurso didático para ilustrar aulas expositivas e, especialmente, localizar lugares, sem problematizar o conteúdo que os mesmos trazem. Sobre este aspecto é que se busca capacitar os futuros professores na elaboração e criação do seu material didático e assim explorar o conteúdo enquanto potencial de aprendizagem geográfica, também como um instrumento científico na construção do conhecimento do espaço (MANTOVANI, 1999, p.34).
Com a preocupação de buscar alternativas metodológicas para uma aprendizagem significativa, este trabalho procurou explorar os conhecimentos prévios dos alunos, por meio da elaboração de mapas temáticos da paisagem geográfica local. Ensinado ao aluno que aquilo que se aprende no espaço escolar, tem relação direta com sua vida cotidiana.

Assim ficou bem claro para nós o objetivo didático do trabalho proposto, o que muitas vezes pode não ser percebido pelo professor, conforme Kaercher (2003, p.188):

A falta de clareza para alguns professores acerca do que deseja ao ensinar Geografia, resulta na pobreza cognitiva e reflexiva, 
pois o que predomina é a lógica informativa, um somatório de dados, não raro faltando um eixo uma espinha dorsal que conduza o raciocínio.

Baseados nestes propósitos o trabalho prático propôs a confecção de mapas com o trajeto casa/universidade do aluno (ou casa/ponto do ônibus ou da van para os alunos de outras cidades), nas seguintes formas:

- um mapa deste trajeto desenhado a mão;

- um mapa do mesmo confeccionado no Google Maps (complementado com desenhos, pontos de referências e anotações complementares);

- um mapa com as mesmas características confeccionado no Google Earth;

- uma imagem do Google Street View, de alguma cidade de sua preferência.

0 trabalho foi iniciado em sala de aula e finalizado em casa, e foi entregue no último dia das atividades, onde foi submetido a avaliação e posteriormente devolvido para ser anexado ao portfólio.

No processo de produção, o aluno constrói o conceito de mapa. Ele precisa se dar conta do que é um mapa e de como é produzido. A representação do espaço é uma ação interiorizada e não simplesmente uma imaginação ou um dado exterior qualquer resultante da ação (ALMEIDA, 2006, p.71).

Segundo ainda Almeida (2006), na evolução histórica do uso dos signos com função social de registro, o mapa foi o instrumento que surgiu quando o homem precisou de um registro espacial fora de sua memória, que lhe permitisse trabalhar com maior número de informações e portanto, manipular maior gama de conhecimentos para interferir sobre a natureza e agir sobre um espaço ausente.

Assim a confecção de mapas favorece e possibilita ao aluno domínio visual do espaço a partir da sua representação, permitindo ao aluno imaginar, criar, explorar, compartilhar e refletir sobre o mapa elaborado.

Na sequência alguns trabalhos para ilustrar como se desenvolveu a dinâmica:

\section{Mapas confeccionados manualmente}

Imagem no 05 - Mapa do trajeto casa/ponto do ônibus

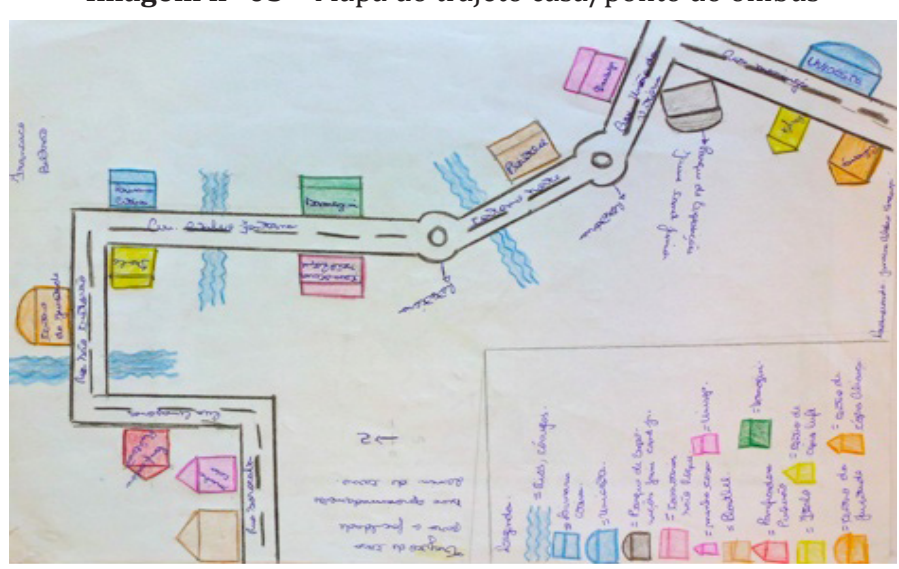

Imagem no 06- Mapa do trajeto casa/ponto do ônibus

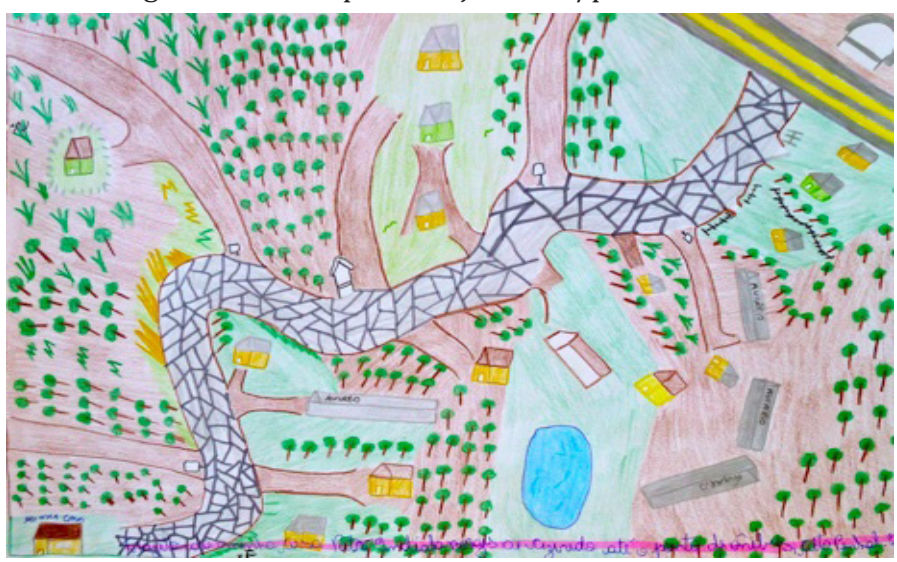

Imagem no 07- Mapa do trajeto casa/ponto do ônibus

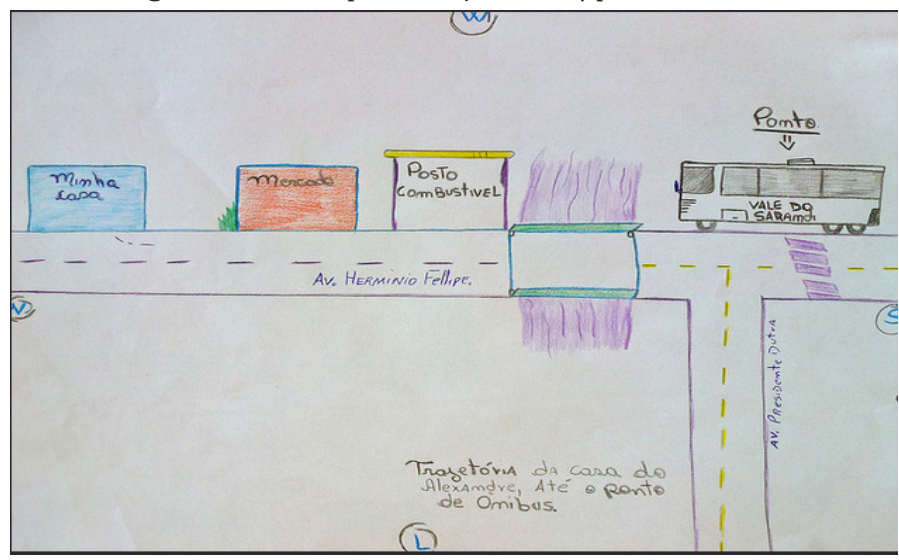

Mapas confeccionados no Google Maps

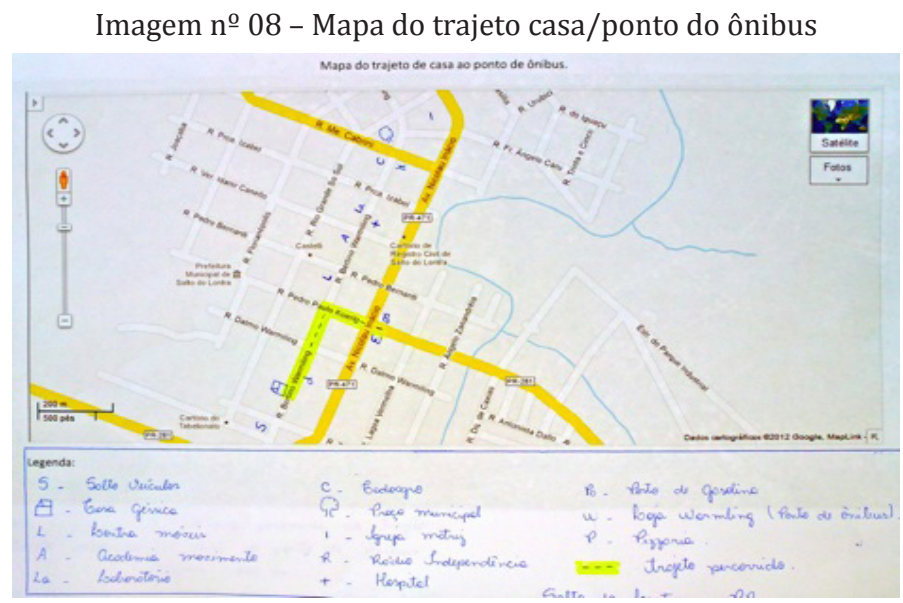

Fonte: Google Maps

Imagem no 09 - Mapa do trajeto casa/universidade

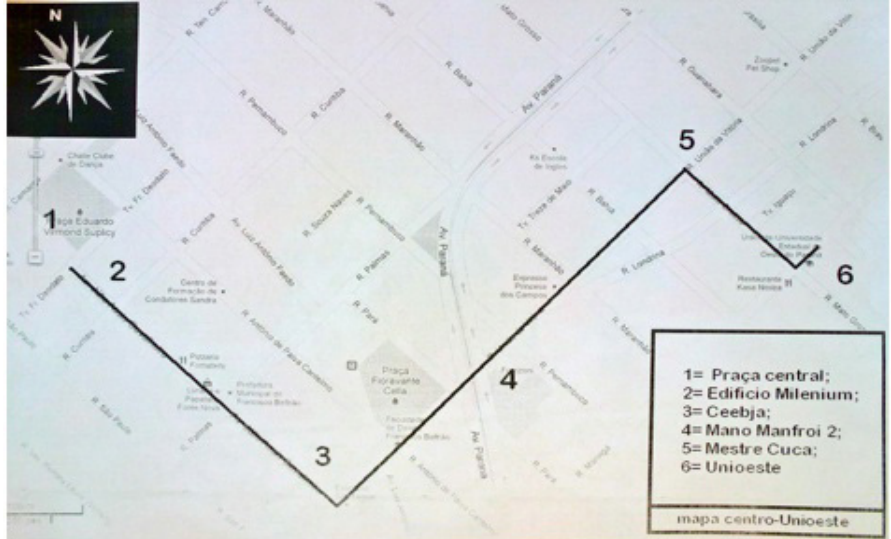

Fonte: Google Maps 


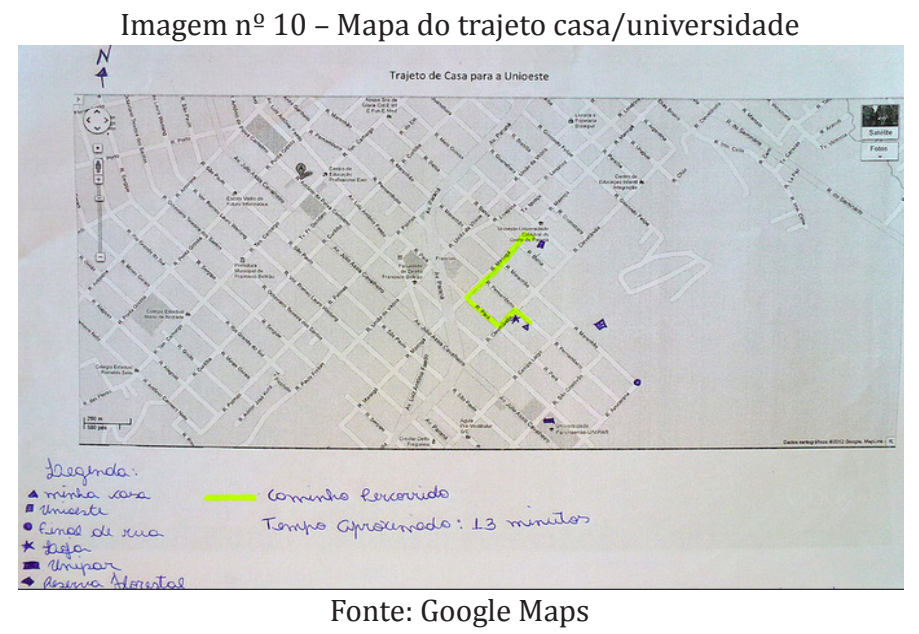

Mapas confeccionados no Google Earth

Imagem no 11 - Mapa do trajeto casa/ponto do ônibus

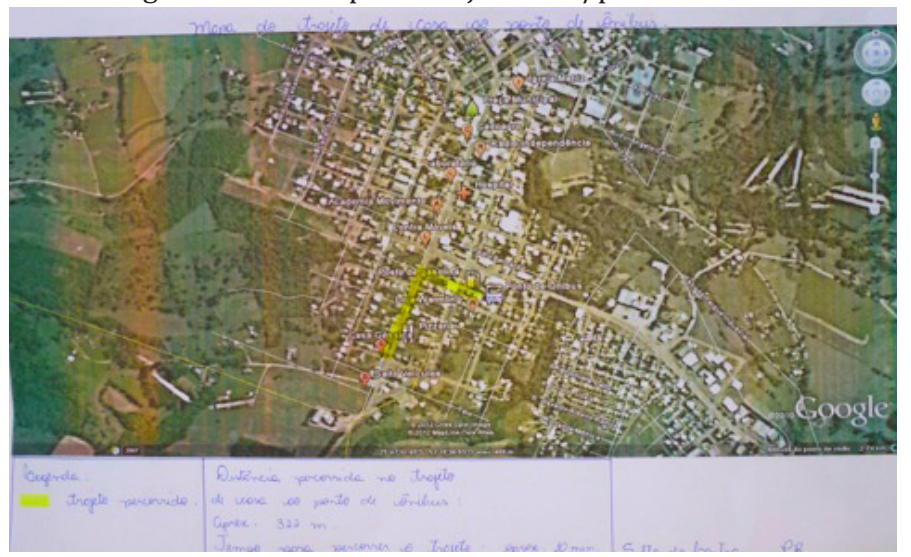

Fonte: Google Earth

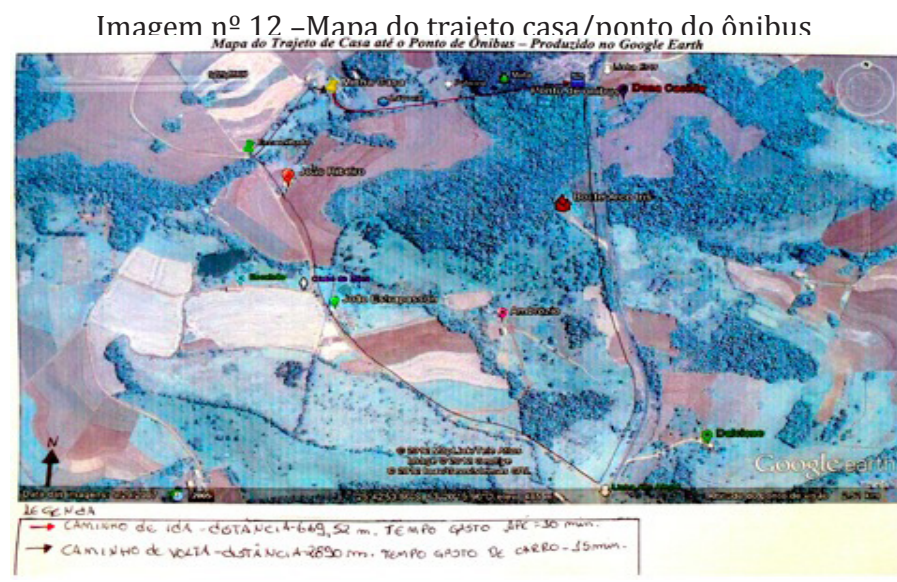

Fonte: Google Earth

Imagem no 13 -Mapa do traieto casa/faculdade

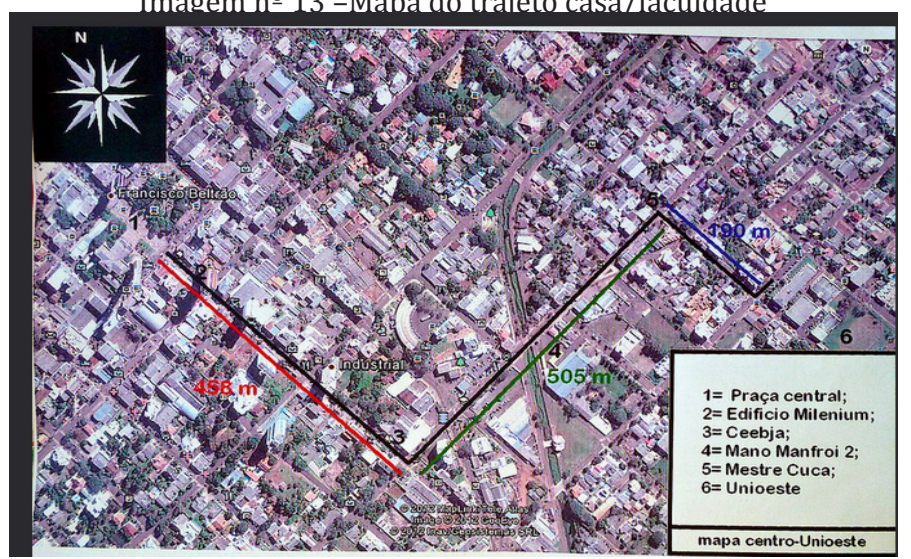

Fonte: Google Earth

\section{Imagens Retiradas do Google Street View}

Imagem no 14 - Ópera de Arame, Curitiba/PR

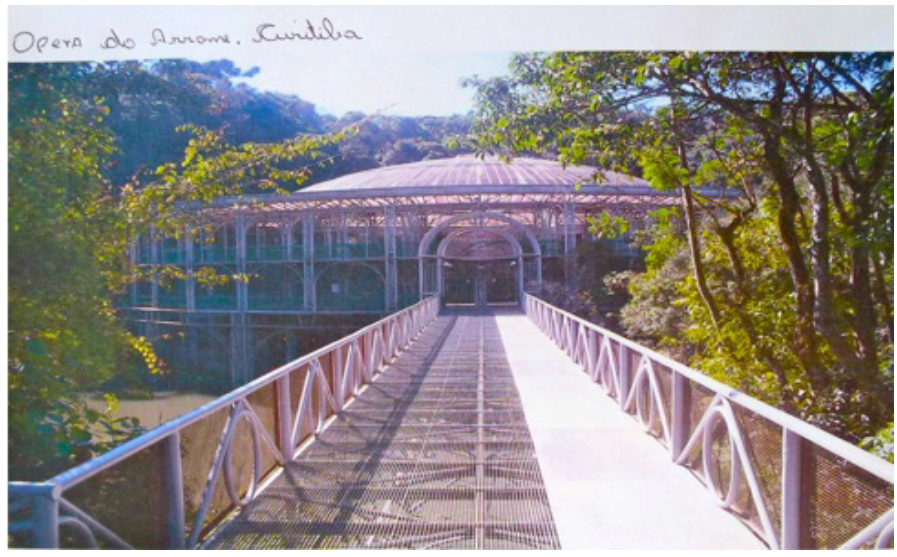

Fonte: Google Street View

Imagem no 15 - Lago Municipal de Cascavel/PR

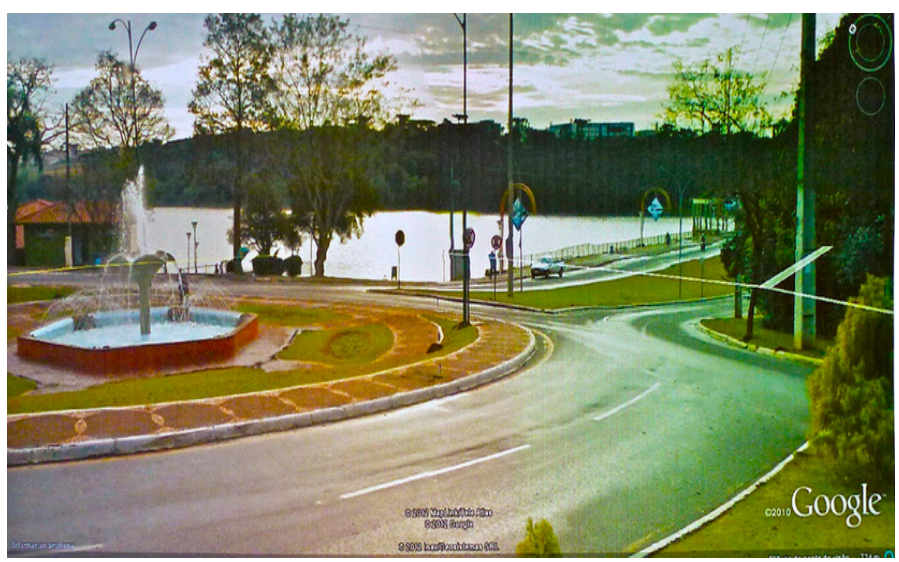

Fonte: Google Street View

\section{Conclusões}

As mais acessíveis tecnologias de informação e de tratamento de dados espaciais digitais (redes, Internet, imageamento remoto e geoprocessamento, entre outras) se tornam, cada dia mais, instrumentos indispensáveis, à medida que possibilitam, além da espacialização da informação, maior acessibilidade, precisão e velocidade na obtenção de dados (XAVIER - DA - SILVA, 2001).

Os programas Google Earth, Maps e Street View, demonstraram ser instrumentos práticos de análise da localização espacial, sua utilidade para as aulas de Geografia é inquestionável, mas também podem servir como ferramenta catalisadora da interdisciplinaridade com outras áreas, num contínuo e dinâmico processo de ensino e aprendizagem. Esse processo pedagógico deve orientar o indivíduo na expressão de suas potencialidades, e desenvolvendo no aluno sua capacidade crítica, com a finalidade de elevar a Geografia, e o estudo de várias disciplinas, a algo prazeroso que instigue cada vez mais o aluno a formular perguntas intrigantes e a buscar respostas coerentes e satisfatórias para sua vida. 
As imagens do Google Earth, Maps e Street View pelo alto apelo visual, contribuem para a função pedagógica de ensinar em sala de aula, pois constatamos que a capacidade de percepção e localização dos alunos foi muito satisfatória.

As atividades desenvolvidas no estágio nos possibilitaram uma reflexão sobre a importância de ser professor, retomando questões didáticas metodológicas, ligadas ao ensino de Geografia e da Cartografia. $\mathrm{Na}$ atualidade ensinar requer planejamento e reestruturação dos temas que serão abordados, para que supram as necessidades dos alunos de graduação, porque serão futuros professores de Geografia.

Concluímos que apresentar as novas tecnologias na Cartografia aos alunos é fundamental, para que consigam interpretar os fatos e fenômenos que acontecem no seu local de vivência e no mundo, auxiliando na formação de cidadãos críticos e capazes de interpretar a dinâmica realidade da qual fazem parte.

\section{Referências}

ALMEIDA, R. D. de. Do desenho ao mapa: iniciação cartográfica na escola. São Paulo: Contexto, 2006.

BRASIL. Lei 9394/96 de 20/12/96 - Lei de Diretrizes e Bases da Educação Nacional. Brasília (DF): Diário Oficial da União, n² 248 de 23/12/1996.

CASTELLAR, S.M.V. Alfabetização em geografia. Espaços da Escola, Ijuí, 2000.

COSTELLA, R. Z.; SCHAFFER, N. O. A Geografia em projetos curriculares: ler o lugar e compreender o mundo. Erechim: Edelbra, 2012.

GO0GLE Earth. Disponível em http://earth.google.com/. Acesso abril de 2013.

HOBSON, A. The Cinemascapist - Street View Disponí- vel em http://www.aaronhobson.com/streetview.html. Acesso abril 2012

KAERCHER, N. A. Desafios e utopias no ensino de Geografia, In: Geografia em sala de aula - práticas e reflexões. Porto Alegre: UFRGS/AGB, 2004, p. 173-188.:

LÉVY, P. As tecnologias das inteligências: o futuro do pensamento na era da informática. Rio de Janeiro: Editora 34, 1993.

MANTOVANI. A.C.D.M. Reflexões sobre o Ensino da Cartografia Temática na Geografia. In: XIX Congresso Brasileiro de Cartografia, Recife, 1999.

MARTINELLI, M. As representações gráficas da Geografia: os mapas temáticos. Tese (livre-docência) - FFLCH - USP, São Paulo, 1999.

MORIN. E. Cultura de Massa no século XX. Rio de Janeiro: Forense, 1997.

PATCHENICK, B. Children Map the World. New York: Esri's Bookstor, 1995.

SECRETARIA DE EDUCAÇÃO FUNDAMENTAL. PCNs - Parâmetros Curriculares Nacionais: Geografia. Brasília: MEC/SEF, 1999.

TV ESCOLA. A História dos Mapas. Acesso em 12/04/12. Disponível em: http://tvescola.mec.gov.br/index. php?option=com_content $\&$ view=category\&id=91\&layou $\mathrm{t}=\mathrm{blog} \&$ Itemid $=225$

VIDAL, A. M.; MAIA, J. E. B.; SANTOS, G. L. Educação, informática e professores. Fortaleza: Edições Demócrito Rocha, 2002.

WOOD, Denis. The power of maps. New York: Guildford Press, 1992.

XAVIER-DA-SILVA, J. Geoprocessamento para Análise Ambiental. Rio de Janeiro: S/Editora, 2001.

\section{CÓMO USAR DE FORMA CREATIVA EL GOOGLE EARTH, MAPS, STREET VIEW Y DIBU- JOS DE MAPAS EN CLASES DE CARTOGRAFIA}

Resumen: En este trabajo se presenta el resultado de la práctica docente del máster en Geografía con estudiantes de la asignatura Cartografía General y Temática de la carrera de Licenciatura en Geografía de la Unioeste (Francisco Beltrão, Paraná, Brasil), realizada en el año de 2012. El objetivo de las clases fue proporcionar a los estudiantes los conocimientos teóricos y prácticos básicos para que entendieran las representaciones cartográficas mediante el uso de la cartografía digital. La metodología utilizada fue la presentación (para el posterior uso) de programas de Google como Earth, Maps y Street View, intercalados con dibujos hechos a mano, aplicados a la elaboración de mapas temáticos en las clases de Cartografía. El resultado obtenido fue la formación básica de esos estudiantes en el uso de las nuevas herramientas de enseñanza proporcionadas por la tecnología de la información y la informática y útiles para las clases de Geografía.

Palabras clave: cartografía digital, mapas, imágenes, tecnolo 